\title{
Extended Adjuvant Endocrine Therapy in Hormone Receptor-Positive Early Breast Cancer
}

\author{
Dara B. Bracken-Clarke Mairi W. Lucas Michaela J. Higgins \\ Department of Medical Oncology, Mater Misericordiae University Hospital, Dublin, Ireland
}

\section{Keywords}

Adjuvant treatment - Aromatase inhibitors .

Breast cancer · Endocrine therapy - Tamoxifen

\section{Summary}

Despite meaningful, incremental improvements in detection, local treatment and adjuvant systemic treatments for breast cancer, there remains a significant risk of late relapse in hormone receptor (HR)-positive disease. 5 years of tamoxifen or an aromatase inhibitor for all patients with HR-positive early breast cancer is considered standard; however, there are now data to support an extended approach using up to 10 years of treatment. This review will provide some historical background on endocrine therapy and summarize the key clinical trials that demonstrate the small absolute benefit of extended adjuvant therapy. We provide suggested treatment algorithms for both premenopausal and postmenopausal patients and an overview of ongoing adjuvant trials.

(c) 2017 S. Karger GmbH, Freiburg

\section{Introduction and Historical Perspective}

Hormonal manipulation in the adjuvant setting for breast cancer, using selective oestrogen receptor-modulating agents (SERMs, i.e. tamoxifen) or aromatase inhibitors (AIs, i.e. anastrozole, letrozole and exemestane), represents arguably the single greatest advance in medical oncology. The 2011 Oxford overview showed tamoxifen to be effective in preventing recurrent oestrogen receptor (ER)-positive breast cancer [1].

The observation that oestrogen production in postmenopausal women is driven by peripheral conversion of androgens to oestro- gens by the enzyme aromatase led to the direct targeting of this molecule with AIs. Tamoxifen was compared head-to-head with AIs over multiple trials including ATAC (Arimidex, Tamoxifen, Alone or in Combination, using anastrozole and tamoxifen, an adjuvant trial) and the combined North American and European studies (in locally advanced or metastatic disease) [2-6]. Together these trials encompassed 1,021 postmenopausal women with breast cancer and demonstrated a progression-free survival (PFS) advantage for 5 years of anastrozole over tamoxifen with a generally tolerable side effect profile. The marginal advantage was small, with an absolute difference in PFS of $3.7 \%$ at a median follow-up of 68 months (hazard ratio (HR) 0.74; $\mathrm{p}=0.0002$ ) [2]. Notably, a significant portion of this benefit was in reduced contralateral breast cancer risk, with a $53 \%$ risk reduction compared to tamoxifen ( $\mathrm{p}=$ 0.001) [2]. A subsequent meta-analysis of these trials by the Early Breast Cancer Trialists' Collaborative Group (EBCTCG) confirmed these data [7].

These reports led to the approval of anastrozole by the Food and Drug Administration (FDA), despite no overall survival (OS) advantage having been demonstrated. 5 years of adjuvant treatment with the irreversible steroidal AI exemestane was compared to anastrozole in the National Cancer Institute of Canada Clinical Trials Group (NCIC CTG) MA.27 study, which demonstrated equivalence in event-free survival (EFS) outcomes [8]. Higher rates of vaginal bleeding and dyslipidaemia were observed with anastrozole whereas exemestane caused higher rates of liver dysfunction [8].

Rotation from tamoxifen to AI therapy after a prespecified period (usually $2-3$ years) was addressed in several trials - in particular, the Breast International Group (BIG) trial [9]. This was a 4-arm study comparing letrozole and tamoxifen as single agents with sequential therapy of 2 and 3 years of each, with $>8,000$ patients randomised. Following publication of the ATAC results, patients on the tamoxifen monotherapy arm were offered selective crossover to the letrozole arm [4]. This confirmed superiority of AIs over tamoxifen in terms of disease-free survival (DFS) (HR

\section{KARGER}

() 2017 S. Karger GmbH, Freiburg

Fax +497614520714 


\section{5 years of tamoxifen versus no tamoxifen*}

Fig. 1. EBCTCG overview: 15 year breast cancer recurrence and mortality rates in early breast cancer with or without 5 years of adjuvant breast cancer treatment. Reprinted with permission from Elsevier [1].

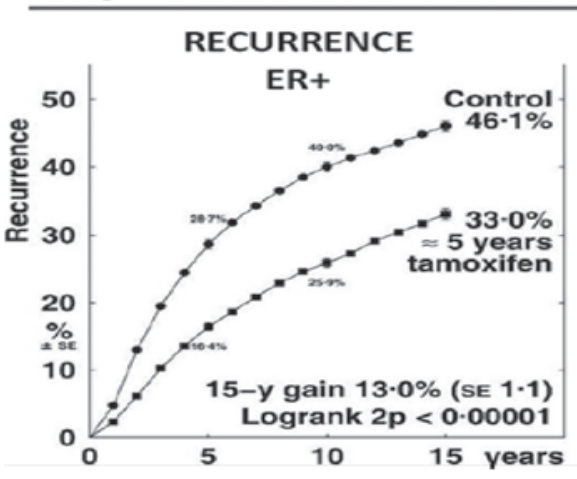

$0.81 ; \mathrm{p}=0.003)$; however, again no significant OS benefit was demonstrated - a recurring theme in these analyses [9]. The crossover arms demonstrated similar efficacy to letrozole monotherapy with a non-significantly increased relapse risk in the tamoxifen $\rightarrow$ letrozole arm.

In terms of the side effect profile, the above trials demonstrated a general concordance of results. Tamoxifen demonstrated higher rates of thromboembolic phenomena, vaginal bleeding and hot flashes; a previously noted suggestion of increased cardiac ischaemic events was not confirmed. AIs demonstrated higher rates of reduced bone mineral density (BMD), arthralgias and myalgias as well as a trend towards increased arteriopathy risk [2-9].

Importantly, the 2011 EBCTCG overview demonstrated that more than half of the recurrences and deaths from early breast cancer occurred between years 5 and 15 after 5 years of adjuvant endocrine therapy [1] (fig. 1). Previous trials had demonstrated the clear superiority of 5 years of tamoxifen over less years of tamoxifen treatment $(74 \%$ vs. $80 \%$ DFS at 5 years in a Swedish study comparing 2 vs. 5 years of tamoxifen [10]). Extrapolating from these results, the potential benefit of prolonging endocrine therapy beyond 5 years was raised. Earlier trials (by the Eastern Cooperative Oncology Group (ECOG), by a Scottish group, and National Surgical Adjuvant Breast and Bowel Project (NSABP) B-14) had demonstrated either equivocal or deleterious outcomes from prolonged therapy [11-13]. This question would be readdressed in the larger ATLAS, aTTom, MA.17 and MA.17R trials.

\section{aTTom and ATLAS - the Case for Prolonged Tamoxifen Therapy}

The Adjuvant Tamoxifen, To Offer More? (aTTom) study represented a UK trial randomising 6,953 (ER+: 2,755, HR?: 4,198 believed to represent approximately $80 \%$ ER+ tumours) early breast cancer patients between 1991 and 2005 to tamoxifen for 5 versus 10 years, with the equivalent international study, Adjuvant Tamoxifen: Longer against Shorter (ATLAS), randomising 12,894 patients $[14,15]$. Of note, there were no specific inclusion or exclusion criteria for stage, surgery, grade or hormonal status - although a subdivision according to hormonal status was undertaken. Al- though a larger accrual had been planned, closure occurred in 2005 based on the positive MA.17 trial [16].

Both aTTom and ATLAS demonstrated individually positive results in terms of both DFS and OS, with the pooled data demonstrating a statistically significant OS advantage favouring prolonged tamoxifen therapy. Compliance with extended tamoxifen therapy was approximately $80 \%$, suggesting overall tolerability of this regimen $[14,15]$.

aTTom demonstrated a significant time-dependent reduction in breast cancer recurrence and breast cancer mortality. Endometrial cancer risk was increased with extended therapy (102 vs. 45 events, relative risk (RR) 2.2; $\mathrm{p}<0.0001)$ [14].

ATLAS data were similar to the above with breast cancer recurrence $R R$ of $0.9(p=0.10)$ in years $5-9$, improving to RR 0.75 after year $10(p=0.003)$; breast cancer mortality $R R$ of $0.97(p=0.74)$ in years 5-9, improving to RR $0.71(\mathrm{p}=0.0016)$ after year 10 . The absolute risk reduction for recurrence was $3.7 \%$ while the absolute risk reduction for mortality was $2.8 \%$. In the extended treatment arm there was a significantly increased risk of pulmonary embolism (RR 1.87; $\mathrm{p}=0.01)$ and the cumulative endometrial cancer risk was $3.1 \%$ over the years $5-14$ compared to $1.4 \%$ for the comparator arm [15].

Overall, aTTom and ATLAS demonstrated the definite efficacy and safety of extended adjuvant endocrine therapy with tamoxifen. Notably, this benefit was preserved across all patient subsets, with no differences noted according to nodal status, age, tumour stage or menopausal status. They also demonstrated a small increased risk of endometrial cancer with low associated mortality - likely due to early-stage detection of these gynaecological tumours. Prolonged follow-up periods are required to demonstrate efficacy of extended adjuvant therapy. The aTTom and ATLAS studies remain the first and only trials of extended treatment in which an OS, in addition to DFS, advantage has been observed.

\section{Extended Endocrine Therapy with an Al after Tamoxifen}

The MA.17 trial was designed to assess the role of extended adjuvant endocrine therapy with an AI (letrozole) for 5 years fol- 
lowing completion of the then standard of care, tamoxifen, for 5 years [16]. From August 1998 to September 2002, 5,187 postmenopausal women (determined by age, oophorectomy status, amenorrhoea and/or follicle-stimulating hormone (FSH)/luteinising hormone (LH) levels) with previous curative primary therapy (including chemotherapy/radiotherapy - as appropriate) who had completed 4.5-6 years of adjuvant tamoxifen for a confirmed hormone receptor-positive $(\mathrm{HR}+)$ early breast cancer. Patients were randomised to letrozole (2,593 patients) versus placebo (2,594 patients). The median age of the participants was 62 years and $46 \%$ had node-positive tumours. The primary endpoint was DFS with secondary endpoints of OS, safety and quality of life (QoL).

The first planned interim analysis (taking place at 2.4 years of therapy) demonstrated a clear DFS advantage for letrozole - DFS rates being $93 \%$ versus $86 \%$ (HR $0.57,95 \%$ confidence interval (CI) $0.43-0.75 ; \mathrm{p}=0.00008$ ) [16]. However, at this point, a significant OS advantage had not been demonstrated (understandable, given the short follow-up), with the 4-year OS being 96\% (letrozole) versus $94 \%$ (placebo), HR for death: 0.76 (but 95\% CI 0.48-1.21; p = 0.25). Adverse events (AEs) were as expected, with significantly higher rates of hot flashes ( $47.2 \%$ vs. $47.5 \%)$, arthralgias ( $21.3 \%$ vs. $16.6 \%$ ) and arthritis (5.6\% vs. $3.5 \%$ ) - including 1 case of grade IV arthritis. Osteoporosis rates were $5.8 \%$ versus $4.5 \%(\mathrm{p}=0.07)$, and fracture rates, $3.6 \%$ versus $2.9 \%(\mathrm{p}=0.24)$. On the basis of the early DFS difference, the monitoring committee recommended unblinding of the trial, and letrozole was offered to those in the placebo arm on ethical grounds [16].

Further interim analysis in 2005 demonstrated similar overall DFS outcomes: 4-year DFS: $94.4 \%$ (letrozole) versus $89.8 \%$ (placebo); $\mathrm{p}<0.001$. In the overall population there was no OS difference; however, a prespecified subgroup analysis demonstrated a significant OS benefit in patients with node-positive disease (HR for death: $0.82,95 \%$ CI $0.38-0.98 ; \mathrm{p}=0.04)[17,18]$.

A later publication used 2 statistical approaches to correct for the likely impact of crossover on the MA.17 results [19]. Using these tools at a median follow-up of 64 months, the HRs of letrozole and placebo were more impressive, with an HR of 0.52 (95\% CI 0.45-0.61; $\mathrm{p}<0.001$ ) for DFS, an HR of 0.51 (95\% CI 0.42-0.61; $\mathrm{p}<0.001)$ for distant DFS (DDFS) and an HR of 0.61 (95\% CI $0.52-0.71 ; \mathrm{p}<0.001)$ for OS.

\section{MA.17R - the Case for Extended Hormonal Therapy with Als}

MA.17R arose as a result of positive findings in the earlier MA.17 trial and its update [16-19]. The MA.17R study assessed the role of extending adjuvant endocrine therapy with an AI (letrozole) in early HR+ postmenopausal breast cancer patients post 4.5-6 years of adjuvant endocrine therapy. Although originally planned to include only those patients who had received an AI, it was expanded to include prior tamoxifen therapy - indeed, these cases ultimately made up the majority. 1,918 patients were randomised
1:1 to letrozole versus placebo from 2004 to 2009; stratification was performed according to age, stage, nodal status and prior endocrine therapy, with similar populations in the treatment and control arms. The median follow-up was $>6.3$ years with relatively good tolerance (discontinuation rate: $5.4 \%$ in the treatment arm vs. $3.7 \%$ in the placebo arm); prespecified QoL scores were either not significantly different (MENQOL score (menopause-specific QoL)) or favoured the letrozole arm at 60 months. Adherence to the trial protocol was only $61 \%$ [20].

The interim results were somewhat disappointing, with a significant but small DFS advantage in the letrozole arm of $95 \%$ versus $91 \%$ (HR for recurrence or contralateral disease: $0.66 ; \mathrm{p}=0.01$ ); notably, no OS advantage was demonstrated [20]. The DFS advantage was largely due to a decreased rate of contralateral breast events in the letrozole arm and was seen across all prespecified subgroups. Toxicities were manageable, with no significant differences in the rates of menopausal symptoms, arthralgias or myalgias or cardiovascular events. A significant increase in the rates of both osteoporosis ( $11 \%$ vs. $6 \%$; $\mathrm{p}<0.001)$ and fractures $(14 \%$ vs. $9 \%$; $\mathrm{p}=$ 0.001 ) was seen in the letrozole arm [20] (table 1).

\section{Other Publications Assessing Al Therapy after Tamoxifen}

Multiple other trials have looked at the duration of AI therapy preceded by tamoxifen treatment; these are summarised in table 1 and 2. The ABCSG6A study (Austrian Breast and Colorectal Cancer Study Group) of 1,135 women did show a statistically significant DFS improvement with extended anastrozole versus placebo (HR 0.62, 95\% CI 0.40-0.96; $\mathrm{p}=0.031$ ) [21]. NSABP-33 was planned to address the role of extended adjuvant endocrine therapy with exemestane for 2 years following completion of 5 years of tamoxifen therapy but did not meet the accrual goals and closed prematurely after 1,562 eligible patients were randomised. Following unblinding, 560/783 patients originally assigned to the exemestane arm continued therapy, with $344 / 779$ patients on the placebo arm crossing over to exemestane (crossover times: 6-24 months). Despite early closure, a non-significant $2 \%$ absolute DFS improvement with exemestane at a median follow-up of 30 months ( $p=0.07$ ) was observed [22]. The DATA trial (Different Durations of Adjuvant Anastrozole after 2 to 3 Years Tamoxifen Therapy in Breast Cancer - NCT00301457), randomising postmenopausal, early breast cancer patients post curative therapy who had completed 2-3 years of adjuvant tamoxifen to either 3 or 6 years of anastrozole, awaits final publication, but preliminary results have shown a non-significant improvement in adjusted DFS [23].

Table 2 summarises the clinical studies of various extended adjuvant approaches that are ongoing, though most are now closed to accrual.

The recent St. Gallen 2017 conference also addressed this issue [24]. The consensus opinion from the expert group favoured extending adjuvant endocrine therapy for at least 5 years (89\% in fa- 
Table 1. Overview of trials of extended adjuvant endocrine therapy beyond 5 years

\begin{tabular}{|c|c|c|c|c|c|}
\hline Trial & $\begin{array}{l}\text { Number of } \\
\text { participants }\end{array}$ & Menopausal status & Trial arms & Prior therapies & Reported outcomes \\
\hline \multicolumn{6}{|c|}{ Treatment with extended tamoxifen } \\
\hline ECOG $[11]$ & 193 & pre- and postmenopausal & $\begin{array}{l}\text { tamoxifen } \\
\text { vs. no therapy }\end{array}$ & $\begin{array}{l}\text { chemotherapy, tamoxifen } \\
\text { ( } 5 \text { years) }\end{array}$ & $\begin{array}{l}\text { RFS: } 85 \% \text { vs. } 73 \%(\mathrm{p}=0.10) \\
\text { OS: } 86 \% \text { vs. } 89 \%(\mathrm{p}=0.52)\end{array}$ \\
\hline Scottish group [12] & 342 & pre- and postmenopausal & $\begin{array}{l}\text { tamoxifen } \\
\text { vs. no therapy }\end{array}$ & tamoxifen \pm radiotherapy & $\begin{array}{l}\text { Event-free HR: } 1.27 \text { (0.87-1.85); } 60 \\
\text { vs. } 49 \text { events }\end{array}$ \\
\hline NSABP B-14 [13] & 1,152 & pre- and postmenopausal & $\begin{array}{l}\text { tamoxifen } \\
\text { vs. placebo }\end{array}$ & tamoxifen \pm radiotherapy & $\begin{array}{l}\text { DFS: } 78 \% \text { vs. } 82 \%(\mathrm{p}=0.03) \\
\text { OS: } 91 \% \text { vs. } 94 \%(\mathrm{p}=0.07)\end{array}$ \\
\hline ATLAS [15] & 6,846 & pre- and postmenopausal & $\begin{array}{l}\text { tamoxifen } \\
\text { vs. placebo }\end{array}$ & $\begin{array}{l}\text { tamoxifen } \pm \text { chemotherapy } \pm \\
\text { radiotherapy }\end{array}$ & $\begin{array}{l}\text { mortality (breast cancer) } \\
\text { RR: } 0.71(\mathrm{p}=0.0016) \text { after year } 10\end{array}$ \\
\hline aTTom [14] & 6,953 & pre- and postmenopausal & $\begin{array}{l}\text { tamoxifen } \\
\text { vs. no therapy }\end{array}$ & $\begin{array}{l}\text { tamoxifen } \pm \text { chemotherapy } \pm \\
\text { radiotherapy }\end{array}$ & $\begin{array}{l}\text { mortality (breast cancer) } \\
\text { RR: } 0.77(\mathrm{p}=0.0016) \text { after year } 10\end{array}$ \\
\hline \multicolumn{6}{|c|}{ Treatment with extended AI } \\
\hline MA.17 [16] & 5,187 & postmenopausal & $\begin{array}{l}\text { letrozole } \\
\text { vs. placebo }\end{array}$ & $\begin{array}{l}\text { tamoxifen } \pm \text { chemotherapy } \pm \\
\text { radiotherapy }\end{array}$ & $\begin{array}{l}\text { DFS HR: } 0.68(0.55-0.83 \\
\mathrm{p}=0.001) ; \text { OS } \\
\text { HR: } 0.98(0.78-1.22, \mathrm{p}=0.85)\end{array}$ \\
\hline NSABP B-33 [22] & 1,598 & postmenopausal & $\begin{array}{l}\text { exemestane } \\
\text { vs. placebo }\end{array}$ & $\begin{array}{l}\text { tamoxifen } \pm \text { chemotherapy } \pm \\
\text { radiotherapy }\end{array}$ & $\begin{array}{l}\text { DFS: } 91 \% \text { vs. } 89 \%(\mathrm{p}=0.07) \\
\text { RFS: } 96 \% \text { vs. } 94 \%(\mathrm{p}=0.004)\end{array}$ \\
\hline ABCSG-6a [21] & 856 & postmenopausal & $\begin{array}{l}\text { anastrozole } \\
\text { vs. placebo }\end{array}$ & $\begin{array}{l}\text { tamoxifen } \pm \text { aminoglutethim- } \\
\text { ide }\end{array}$ & $\begin{array}{l}\text { recurrence HR: } 0.64(0.41-0.99 \\
p=0.047)\end{array}$ \\
\hline MA.17R [20] & 1,918 & postmenopausal & $\begin{array}{l}\text { letrozole } \\
\text { vs. placebo }\end{array}$ & $\begin{array}{l}\text { tamoxifen } \pm \text { chemotherapy } \pm \\
\text { radiotherapy }\end{array}$ & $\begin{array}{l}\text { DFS: } 95 \% \text { vs. } 91 \% \text {; recurrent } \\
\text { disease HR: } 0.66, p=0.01 ; \\
\text { OS: } 93 \% \text { vs. } 94 \% \text { (HR: } 0.97, p=0.83 \text { ) }\end{array}$ \\
\hline
\end{tabular}

Table 2. Ongoing extended adjuvant endocrine therapy trials

\begin{tabular}{|c|c|c|c|c|}
\hline Trial & Initial treatment & Randomisation arms & NCT trial code & Endpoints \\
\hline DATA & tamoxifen $2-3$ years & anastrozole 6 vs. 3 years & NCT00301457 & $\begin{array}{l}\text { primary: DFS; secondary: OS, safety, } \\
\text { contralateral breast cancer }\end{array}$ \\
\hline NSABP B- 42 & $\begin{array}{l}\text { AI or alternating tamoxifen } \\
\text { and AI for } 5 \text { years }\end{array}$ & letrozole vs. placebo & NCT00382070 & $\begin{array}{l}\text { primary: DFS; secondary: OS, } \\
\text { fracture, recurrence, arterial thrombosis }\end{array}$ \\
\hline SALSA & $\begin{array}{l}\text { undifferentiated endocrine } \\
\text { therapy for } 5 \text { years }\end{array}$ & anastrozole for 5 vs. 2 years & NCT00295620 & $\begin{array}{l}\text { primary: DFS; secondary: OS, fracture, } \\
\text { second malignancy }\end{array}$ \\
\hline GIM4 & $\begin{array}{l}\text { tamoxifen } 2-3 \text { years followed } \\
\text { by letrozole to } 5 \text { years }\end{array}$ & $\begin{array}{l}\text { cessation at } 5 \text { years endocrine } \\
\text { therapy vs. } 7-8 \text { years therapy }\end{array}$ & NCT01064635 & primary: DFS; secondary: OS, safety \\
\hline SOLE & $\begin{array}{l}\text { undifferentiated endocrine } \\
\text { therapy for } 5 \text { years }\end{array}$ & $\begin{array}{l}\text { continuous vs. intermittent } \\
\text { letrozole for } 5 \text { years }\end{array}$ & NCT00553410 & $\begin{array}{l}\text { primary: DFS; secondary: OS, AEs, } \\
\text { local vs. distant recurrence }\end{array}$ \\
\hline
\end{tabular}

NCT $=$ Nationales Centrum für Tumorerkrankungen (National Center for Tumor Diseases), NSABP = National Surgical Adjuvant Breast and Bowel Project, $\mathrm{AI}=$ aromatase inhibitor, $\mathrm{DFS}=$ disease-free survival, $\mathrm{OS}=$ overall survival, $\mathrm{AE}=$ adverse event .

vour) and some arguing to extend therapy for a further 5 years ( 15 years endocrine therapy, $66 \%$ in favour) - in cases deemed at high risk of relapse. AI therapy was favoured over tamoxifen in the postmenopausal setting, with tamoxifen for 10 years favoured in the premenopausal setting. The calculation of risk was somewhat controversial, with only node-positive patients felt to have a proven survival benefit; the role of risk scores is discussed below.

\section{Risk Scores for Recurrence}

Using molecular assays to risk-stratify early breast cancer patients has become increasingly routine procedure. The most widely used of these, Oncotype DX (by Genomic Health), is highly effective in assessing the early recurrence risk (within 5 years); however, it is less helpful in quantifying later recurrence $[25,26]$. Similar characteristics (with accurate assessment of the early recurrence 


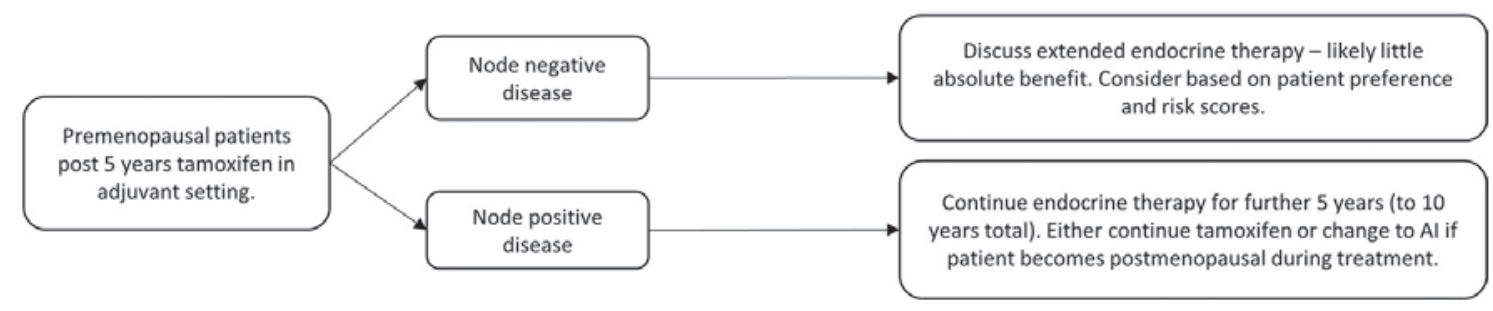

Fig. 2. Proposed algorithm for extending adjuvant endocrine therapy beyond 5 years - tolerance dependent.

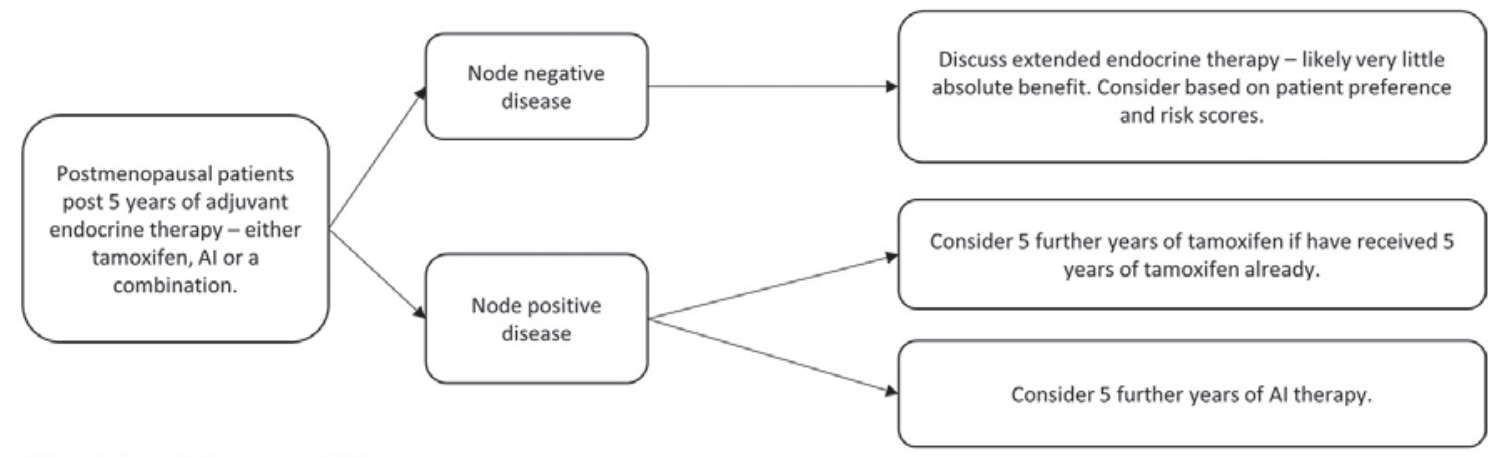

Abbreviations: $\mathrm{Al}=$ Aromatase inhibitor risk but poor quantification of the later recurrence risk) have been noted with other molecular assays, including Mammaprint and the IHC4 score (summarising 4 immunohistochemical parameters) [27, 28]. The Prediction Analysis of Microarray 50 (PAM50) assay and its resultant risk of recurrence (ROR) score (assessing 50 genes by quantitative polymerase chain reaction ( $\mathrm{qPCR}$ ) with subtyping of the lesions into luminal A, luminal B, human epidermal growth factor receptor 2 (HER2)-enriched and basal-like types) appears to offer more long-term predictive data with superior recurrence risk quantification in the 5-10-year range [29].

The breast cancer index (BCI) is another score which combines 2 separate assays - the HOXB13/IL17BR (H/I) ratio test and the molecular grade index (MGI) assay, the former of which is highly predictive of late recurrence - yielding a predictive score relevant in both the short and long term, which was retrospectively validated using material from the ATAC trial $[30,31]$. Regarding its role in determining the duration of adjuvant endocrine therapy, a post-hoc analysis (with all the caveats this implies) was performed on a subset of 83 recurrences matched to 166 non-recurrences in the aforementioned MA.17 trial [32]. A high H/I recurrence score was associated with a significant benefit from extended letrozole therapy with an odds ratio (OR) of 0.35 (95\% CI 0.16-0.75; $\mathrm{p}=0.007$ ).

The opinion at the St. Gallen 2017 International Breast Conference was divided on the role of risk scores as a means to decide on the duration of adjuvant endocrine therapy, with $46 \%$ of the experts in favour and 50\% opposed to their use in this setting [24]. This is a matter of controversy; however, one should remember that the original validation and licensing of the most popular assay, Oncotype DX, is in $\mathrm{HR}+$, node-negative disease - despite its use in longer-term prediction and other breast cancer types. Furthermore, these assays only predict recurrence, not survival (which may or may not be influenced by modifying endocrine therapy); also, the nodal status appears to be a greater predictor of recurrence - as emphasised by the St. Gallen 2017 consensus [24].

The EndoPredict assay with its EPclin score offers an alternative approach [33]. This test combines prognostic information from an 8-gene signature (EP score) with tumour size and nodal status. When compared to the Oncotype DX score, it seemed to provide better prognostication regarding the risk of recurrence in years 5-10 after endocrine therapy; however, it remains to be seen whether treating these relatively higher-risk patients with longerterm endocrine therapy has an impact on survival [34].

\section{A Word about Menopausal Status}

A suggested algorithm for the selection of adjuvant therapy for both pre- and postmenopausal women is shown in figure 2. Several trials including the Suppression of Ovarian Function Trial (SOFT) and the Tamoxifen and Exemestane Trial (TEXT) have examined the impact of ovarian suppression in addition to 5 years of either tamoxifen or AI therapy in premenopausal women [35, 36]. A combined approach provides a small DFS advantage with an increase in the incidence of menopausal, sexual and musculoskeletal symptoms and without an OS advantage. To our knowledge, no data are available to compare the efficacy of combined ovarian suppression plus endocrine therapy for 5 years to sequential endocrine treatment for more than 5 years or endocrine therapy with more than 5 years of ovarian suppression. For our youngest patients who remain premenopausal on completion of 5 years of tamoxifen, a further 5 years of tamoxifen can be considered, but the vast majority of women will either be postmenopausal at diagnosis or will have become so after 5 years of endocrine therapy and therefore will have the option of extended therapy with an AI. 


\section{Future Directions for Adjuvant Endocrine Therapy}

Almost all advanced ER-positive breast tumours become resistant to endocrine manipulations over time. The observance of early and late relapses during adjuvant endocrine therapy suggests a combination of de novo and acquired resistance. Thus there has been intense interest and research in the potential blockade of resistant signalling pathways in breast cancer cells. The combination of targeted agents and standard endocrine therapy is being examined in multiple ongoing studies, e.g. NCT01864746 (PENELOPEB study) and NCT02513394 (PALLAS), which will examine the role of palbociclib in addition to standard adjuvant endocrine therapy in early breast cancer patients with residual disease after neoadjuvant chemotherapy and among women with stage II and III breast cancer, respectively. The ongoing NCT02115282 trial is studying the impact of ribociclib. Drug classes being incorporated include mammalian target of rapamycin (mTOR), cyclin-dependent kinase (CDK) 4/6, phosphoinositide 3-kinase (PI3 kinase) and histone deacetylase inhibitors.

The vast majority of women with ER-positive early breast cancer can now be expected to survive their disease. Since adjuvant therapies are already providing great cancer control, the demonstration of clinically meaningful further benefit from any new intervention will require costly clinical trials involving many thousands of patients with years of follow-up.

\section{Conclusions}

Women with early breast cancer are surviving longer without recurrence of their cancer than ever before, due to incremental improvements in detection, local treatments and systemic therapies. Adjuvant endocrine therapy is recommended for all patients with ER-positive breast cancers. There are an increasing number of endocrine manipulations available and, while 5 years of adjuvant treatment remains a standard, safety data and DFS advantage have been demonstrated with extended treatment for up to 10 years. We recommend careful consideration of an individual's risk of relapse, likelihood of toxicities, estimated absolute benefit and patient preference before recommending any particular approach. For the majority of patients, 5 years of an AI or a combination of some years of tamoxifen followed by 5 years of an AI will be adequate. For women with node-positive disease at presentation who have tolerated 5 years of adjuvant treatment with either tamoxifen or AI, it is reasonable to offer an extended course of treatment to provide a further small DFS advantage.

\section{Disclosure Statement}

The authors declare no conflicts of interest in writing the article or the conclusions drawn.

\section{References}

1 Early Breast Cancer Trialists' Collaborative Group (EBCTCG): Relevance of breast cancer hormone receptors and other factors to the efficacy of adjuvant tamoxifen: patient-level meta-analysis of randomised trials. Lancet 2011;378:771-784.

2 ATAC Trialists' Group: Results of the ATAC (Arimidex, Tamoxifen, Alone or in Combination) trial after completion of 5 years' adjuvant treatment for breast cancer. Lancet 2005;365:60-62.

3 Nabholtz JM, Buzdar A, Pollak M, et al.: Anastrozole is superior to tamoxifen as first-line therapy for advanced breast cancer in postmenopausal women: results of a North American multicenter randomized trial. Arimidex Study Group. J Clin Oncol 2000;18: 3758-3767.

4 Bonneterre J, Buzdar A, Nabholtz JM, et al.: Anastrozole is superior to tamoxifen as first-line therapy in hormone receptor positive advanced breast carcinoma. Cancer 2001;92:2247-2258.

5 Gluck S: Anastrozole is superior to tamoxifen as firstline therapy in hormone receptor-positive advanced breast carcinoma. Cancer 2001;95:2442-2443.

6 Bonneterre J, Thürlimann B, Robertson JFR, et al.: Anastrozole versus tamoxifen as first-line therapy for advanced breast cancer in 668 postmenopausal women: results of the tamoxifen or arimidex randomized group efficacy and tolerability study. J Clin Oncol 2000;18:3748-3757.

7 Dowsett M, Cuzick J, Ingle J, et al.: Meta-analysis of breast cancer outcomes in adjuvant trials of aromatase inhibitors versus tamoxifen. J Clin Oncol 2010;28: 509-518.

8 Goss PE, Ingle JN, Pritchard KI, et al.: Exemestane versus anastrozole in postmenopausal women with early breast cancer: NCIC CTG MA.27 - a randomized controlled phase III trial. J Clin Oncol 2013;31:1398-1404.
9 The Breast International Group (BIG) 1-98 Collaborative Group: A comparison of letrozole and tamoxifen in postmenopausal women with early breast cancer. $\mathrm{N}$ Engl J Med 2005;353:2747-2757.

10 Swedish Breast Cancer Cooperative Group: Randomized trial of two versus five years of adjuvant tamoxifen for postmenopausal early stage breast cancer. J Natl Cancer Inst 1996;88:1543-1549.

11 Tormey DC, Gray R, Falkson H: Postchemotherapy adjuvant tamoxifen therapy beyond five years in patients with lymph node-positive breast cancer. J Natl Cancer Inst 1996;88:1828-1833.

12 Stewart HJ, Prescott RJ, Forrest AP: Scottish adjuvant tamoxifen trial: a randomized study updated to 15 years. J Natl Cancer Inst 2001;93:456-462.

13 Fisher B, Dignam J, Bryant J, Wolmark N: Five versus more than five years of tamoxifen for lymph nodenegative breast cancer: updated findings from the National Surgical Adjuvant Breast and Bowel Project B-14 randomized trial. J Natl Cancer Inst 2001;93: 684-690.

14 Gray RG, Rea D, Handley K, et al.: aTTom: Long-term effects of continuing adjuvant tamoxifen to 10 years versus stopping at 5 years in 6,953 women with early breast cancer. J Clin Oncol 2013;31(suppl):5-5.

15 Davies C, Pan H, Godwin J, et al.: Long-term effects of continuing adjuvant tamoxifen to 10 years versus stopping at 5 years after diagnosis of oestrogen receptorpositive breast cancer: ATLAS, a randomised trial. Lancet 2013;381:805-816.

16 Goss PE, Ingle JN, Martino S, et al.: Randomized trial of letrozole following tamoxifen as extended adjuvant therapy in receptor-positive breast cancer: updated findings from NCIC CTG MA.17. J Natl Cancer Inst 2005;97:1262-1271.
7 Goss PE, Ingle JN, Pater JA, et al.: Late extended adjuvant treatment with letrozole improves outcome in women with early-stage breast cancer who complete 5 years of tamoxifen. J Clin Oncol 2008;26:1948-1955.

18 Goss PE, Ingle JN, Martino S, et al.: Randomized trial of letrozole following tamoxifen as extended adjuvant therapy in receptor-positive breast cancer: updated findings from NCIC CTG MA.17. J Natl Cancer Inst 2015;97:1262-1271.

19 Jin H, Tu D, Zhao N, et al.: Longer-term outcomes of letrozole versus placebo after 5 years of tamoxifen in the NCIC CTG MA.17 trial: analyses adjusting for treatment crossover. J Clin Oncol 2012;30:718-721.

20 Goss PE, Ingle JN, Pritchard KI, et al.: Extending aromatase-inhibitor adjuvant therapy to 10 years. $\mathrm{N}$ Engl J Med 2016;375:209-219.

21 Jakesz R, Greil R, Gnant M, et al.: Extended adjuvant therapy with anastrozole among postmenopausal breast cancer patients: results from the randomized Austrian Breast and Colorectal Cancer Study Group Trial 6a. J Natl Cancer Inst 2007;99:1845-1853.

22 Mamounas EP, Jeong J-H, Wickerham DL, et al.: Benefit from exemestane as extended adjuvant therapy after 5 years of adjuvant tamoxifen: intention-to-treat analysis of the National Surgical Adjuvant Breast and Bowel Project B-33 trial. J Clin Oncol 2008;26:19651971.

23 Tjan-Heijnen VC, Van Hellemond IE, Peer PG, et al.: First results from the multicenter phase III DATA study comparing 3 versus 6 years of anastrozole after 2-3 years of tamoxifen in postmenopausal women with hormone receptor-positive early breast cancer; in: Proceedings of the 2016 San Antonio Breast Cancer Symposium, December 6-10, San Antonio, 2016. Cancer Res 2017;77:abstr S1-03. 
24 Gnant M, Harbeck N, Thomssen C, et al.: St. Gallen/ Vienna 2017: A brief summary of the consensus discussion about escalation and de-escalation of primary breast cancer treatment. Breast Care 2017;12:102-107.

25 Paik S, Shak S, Tang G, et al.: A multigene assay to predict recurrence of tamoxifen-treated, node-negative breast cancer. N Engl J Med 2004;351:2817-2826.

26 Sparano JA, Gray RJ, Makower DF, et al.: Prospective validation of a 21-gene expression assay in breast cancer. N Engl J Med 2015;373:2005-2014.

27 Slodkowska EA, Ross JS: MammaPrint 70-gene signature: another milestone in personalized medical care for breast cancer patients. Expert Rev Mol Diagn 2009; 9:417-422.

28 Yeo B, Zabaglo L, Hills M, et al.: Clinical utility of the IHC4+C score in oestrogen receptor-positive early breast cancer: a prospective decision impact study. $\mathrm{Br} \mathrm{J}$ Cancer 2015;113:390-395
Dowsett M, Sestak I, Lopez-Knowles E, et al.: Comparison of PAM50 risk of recurrence score with Oncotype DX and IHC4 for predicting risk of distant recurrence after endocrine therapy. J Clin Oncol 2013; 31:2783-2790.

30 Jerevall P-L, Ma X-J, Li H, et al.: Prognostic utility of HOXB13:IL17BR and molecular grade index in earlystage breast cancer patients from the Stockholm trial. Br J Cancer 2011;104:1762-1769.

31 Sgroi DC, Sestak I, Cuzick J, et al.: Prediction of late distant recurrence in estrogen receptor positive breast cancer patients: prospective comparison of the Breast Cancer Index (BCI), Oncotype DX recurrence score, and IHC4 in TransATAC. Lancet Oncol 2013;14: 1067-1076.

32 Sgroi DC, Carney E, Zarrella E, et al.: Prediction of late disease recurrence and extended adjuvant letrozole benefit by the HOXB13/IL17BR biomarker. J Natl Cancer Inst 2013;105:1036-1042.
33 Filipits M, Rudas M, Jakesz R, et al.: A new molecular predictor of distant recurrence in ER-positive, HER2negative breast cancer adds independent information to conventional clinical risk factors. Clin Cancer Res 2011;17:6012-6020.

34 Buus R, Sestak I, Kronenwett R, et al.: Comparison of EndoPredict and EPclin with Oncotype DX recurrence score for prediction of risk of distant recurrence after endocrine therapy. J Natl Cancer Inst 2016;108(11).

35 Francis PA, Regan MM, Fleming JF, et al.: Adjuvant ovarian suppression in premenopausal breast cancer. N Engl J Med 2015;372:436-446.

36 Pagani O, Regan MM, Walley BA, et al.: Adjuvant exemestane with ovarian suppression in premenopausal breast cancer. N Engl J Med 2014;371:107-118. 